\title{
TEORIA DO POSICIONAMENTO E TERAPIA FAMILIAR: CRIANDO NOVAS POSIÇÕES DISCURSIVAS NA RELAÇÃO ENTRE MÃE E FILHO
}

\author{
POSITIONING THEORY AND FAMILY THERAPY: CREATING NEW DISCURSIVE \\ POSITIONS IN THE MOTHER-CHILD RELATIONSHIP
}

\begin{abstract}
RESUMO: Seguindo a premissa Construcionista Social de que 0 indivíduo se constitui nas relações através da linguagem e partindo de um contexto prático do atendimento com uma família, 0 objetivo deste artigo é dar visibilidade ao processo de construção de novas posições discursivas para a relação de uma mãe e um filho, a partir do foco no processo de comunicação e do uso de uma metáfora. Teoricamente, nos apoiamos na compreensão do self em sua dimensão relacional. Metodologicamente, utilizamos a teoria do posicionamento como um recurso para dar visibilidade para o processo discursivo em terapia familiar, no qual uma mãe e um filho negociam posições alternativas para seu relacionamento. Concluímos, pela utilidade da teoria do posicionamento na experiência clínica, por permitir colocar em ação a ampliação da noção de identidade, substituindo o enfoque na unicidade pela possibilidade de múltiplas descrições de self.
\end{abstract}

PALAVRAS-CHAVE: Terapia Familiar; Teoria do Posicionamento; Construcionismo Social; Self Relacional; Práticas Discursivas.
ABSTRACT: Following the Social Construction premise that the individual is constituted in relationships through language and starting from a family therapy context, the purpose of this article is to give visibility to the process of constructing more useful discursive positions for the relation of a mother and a child, from the focus on the communication process and the use of a metaphor. Theoretically, we rely on the understanding of the relational self. Methodologically, we use positioning theory as a resource to give visibility to the discursive process in family therapy, in which a mother and child negotiate alternative positions for their relationship. We conclude by the usefulness of using the theory of positioning in clinical practice, because it allows to put into practice the expansion of the notion of identity, replacing the focus on oneness with the possibility of multiple descriptions of self.

KEYWORDS: Family Therapy; Positioning Theory; Social Constructionism; Relational Self; Discursive Practices.

\section{INTRODUÇÃO}

Como responder à pergunta sobre o que é ser uma pessoa? As possíveis respostas variam de acordo com o campo. Podem vir da filosofia, da religião, da ciência ou de outros tantos domínios. Tradicionalmente, a cultura ocidental, assim como a psicologia, tem uma descrição essencialista do indivíduo, cujas ações surgem de dentro para fora. Ainda nessa visão, a maneira como o indivíduo se comporta na sociedade depende de uma instância interna coesa, organizadora de suas ações, isto é, o conceito de pessoa problemática ou normal,
LETÍCIA DE AZEVEDO POZZER $^{1}$

ENEIDA DE DUARTINA FERNANDES NOVAES ${ }^{1}$

${ }^{1}$ Instituto Conversações, Ribeirão Preto/SP,Brasil
Recebido em: 12/09/2019 Aprovado em: 20/10/2019 
por exemplo, fica atrelado à coerência com que ela articula seu conjunto de características pessoais (Rasera \& Japur, 2007).

Na década de 1970, o pensamento pós-moderno expandiu-se para diversos campos do conhecimento, inclusive, nas ciências psicológicas. Alguns autores, apoiados em uma visão que leva em conta o contexto histórico e cultural, propuseram-se a questionar os efeitos da manutenção de uma perspectiva pautada na ideologia individualista e apontaram alguns desses efeitos, tais como o isolamento, a alienação, crenças firmadas na autossatisfação, relacionamentos que possuem caráter secundário, artificial e temporário, competitividade; a criação de instituições de vigilância com ações como punição, prisão, e extinção do indivíduo, além da ausência de um olhar sistêmico, ignorando condições sociais efetivas onde as pessoas vivem (Rasera \& Japur, 2007).

Nessa direção, também os pressupostos que embasaram as respostas sobre o que é ser uma pessoa sofreram um grande giro e se distanciaram do discurso essencialista do indivíduo. Moveram-se, assim, na direção do entendimento sobre um indivíduo que se constitui nas relações, sendo a linguagem geradora da interação e a troca entre as pessoas. Dito de outro modo, compreende-se que as pessoas constroem a si mesmas e a seu mundo nas relações (Guanaes \& Japur, 2003).

$\mathrm{O}$ aporte para seguirmos com esses pressupostos vem do movimento Construcionista Social, cujo discurso "em sua crítica às concepções realistas, empiristas e essencialistas do mundo, acaba por enfatizar os processos sociais e discursivos de construção do mundo" (Rasera \& Japur, 2007, p. 10). Isso também inclui olhar para a constituição do indivíduo no plano relacional, onde a noção de self é entendida como uma construção social, dependente das "práticas discursivas nas quais as pessoas dão sentido ao mundo e às próprias ações" (Guanaes \& Japur, 2003, p. 135).

Ao compreendermos o indivíduo em sua dimensão relacional, histórica e socialmente situado e coerente com os pressupostos construcionistas sociais, não estamos desconsiderando outros discursos sociais acerca do fenômeno da construção do self, como, por exemplo, o das emoções e memórias. Buscamos, sim, ir para além da retórica essencialista como o aspecto definidor da experiência individual. Com isso, ampliamos a discussão para uma outra possibilidade, na qual dois movimentos são importantes: por um lado, situamos qualquer discurso sobre o self como um produto de determinados modos de relação social, marcado histórica e culturalmente; por outro lado, buscamos criar novos vocabulários de compreensão do self, no qual este passa a ser descrito como constituído e reconstituído nas práticas discursivas das quais participa (Guanaes \& Japur, 2003; McNamee \& Gergen, 1999).

Em nossa trajetória de formação como terapeutas familiares, essa visão foi particularmente importante durante um atendimento com uma mãe e um filho, no qual nosso foco estava em trabalhar o que acontece entre eles, no modo como se comunicavam, como construíam sentidos juntos, além de flexibilizar posições cristalizadas que impediam um bom diálogo, ao invés de enfatizar "aspectos internos" de cada participante que precisavam ser mudados para melhorar a relação. Usando o relacionamento de mãe e filho como exemplo para ilustrar os jogos de posicionamento, podemos dizer que, 
ao transformar a posição de "mãe é quem ensina o filho" para a posição de "mãe que também aprende com filho", é possível que a mãe tenha condições de oferecer uma escuta mais acolhedora, valorizando as falas do mesmo.

Partindo do contexto prático do atendimento com esta família, o objetivo neste artigo é dar visibilidade ao processo de construção de posições discursivas mais úteis para a relação de mãe e filho a partir do foco no processo de comunicação e do uso de uma metáfora. Teoricamente, nos apoiamos na compreensão do self em sua dimensão relacional e, nesse sentido, optamos metodologicamente pela utilização da Teoria do Posicionamento (van Langenhove \& Harré, 1999) como instrumento de análise para visualizar o processo discursivo em terapia familiar, no qual uma mãe e um filho negociam posições alternativas que culminam na melhora de seu relacionamento. Consideramos a Teoria do Posicionamento para este trabalho justamente por sua ênfase no caráter dinâmico das relações e por ampliar a noção de identidade substituindo o enfoque na unicidade pela possibilidade de múltiplas descrições de self.

Para isso, nossa argumentação se dará da seguinte maneira ao longo do texto: primeiramente, situaremos os leitores sobre conceitos da Teoria do Posicionamento que serão utilizados no momento da análise e que sustentam a ideia de um self relacional. Em seguida, mostraremos a importância de pensar o self relacional nas práticas de terapia familiar orientadas por uma epistemologia construcionista social.Buscamos, dessa perspectiva, olhar para como as pessoas se constituem nas relações, por meio das posições que ocupam, em detrimento de abordar os problemas como efeitos de dificuldades individuais. Por fim, usando a tríade conceitual posição, força social da ação e linha de história, apresentaremos a análise de momentos de uma sessão com uma família, elucidando como fomos desenvolvendo recursos conversacionais que permitiram a construção de novas posições que puderam favorecer a comunicação entre uma mãe e seu filho, apontando, afinal, para a relevância de trabalhar com a noção de self relacional na prática clínica.

\section{TEORIA DO POSICIONAMENTO}

As primeiras noções de posição e posicionamento foram introduzidas por Hollway (1984) em seu estudo dos processos de construção de subjetividade nas relações heterossexuais. Para esta autora, trabalhar com a ideia de posição no discurso servia para observar os direitos e deveres de fala entre homens e mulheres durante o momento de interação. Ao propor o conceito, Hollway (1984) buscava compreender por que mulheres falam menos na companhia de homens e mais num grupo composto só por mulheres (van Langenhove \& Harré, 1999). A autora apontava que certos discursos, nesse caso, os heteronormativos, tornavam possíveis certas posições aos interlocutores que, por sua vez, estavam a serviço de certas funções sociais.

Desde então, o conceito se ampliou na tentativa de compreender como as pessoas constroem suas identidades discursivamente, em relação aos outros e às funções sociais, assumindo para si mesmas ou para os outros determinadas posições (Guanaes \& Japur, 2008). Para van Langenhove e Harré (1999):

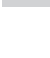

-


o posicionamento pode ser entendido como a construção discursiva de histórias pessoais que torna as ações das pessoas inteligíveis e relativamente determinadas como atos sociais, e dentro das quais os membros de uma conversa têm localizações específicas. (p.16)

Van Langenhove e Harré (1999) argumentam que a percepção que temos sobre quem somos no mundo social surge de um contínuo movimento de reivindicar, aceitar e refutar posições no discurso. Para estes autores, o conceito de posição diz respeito a "um grupo complexo de atributos pessoais e genéricos, estruturado de vários modos, que influencia nas possibilidades de ação pessoal" (van Langenhove \& Harré, 1999. p. 01) e se referem aos lugares sociais assumidos e negociados pelos indivíduos em suas interações.

Esses atributos tanto denotam posições morais e sociais reconhecidas, como, por exemplo, mãe, filho, médico etc., quanto variações destas posições, como, por exemplo, filho brincalhão, mãe cuidadosa, médico tranquilo etc. Entretanto, diferente da noção de papéis, que são estáveis e fixos, uma posição não carrega um significado em si mesma, mas, ao invés disso, seus sentidos são construídos nas interações. Os teóricos do posicionamento opõem-se ao conceito de papel devido à sua condição estática e reducionista. Eles argumentam que não existem papéis pré-fabricados, mas que nós criamos posições para nós mesmos e outros nas inúmeras linhas de histórias trazidas nas interações (Guanaes \& Japur, 2008; Oliveira, Guanaes, \& Costa, 2003).

Dito isso, pode-se dizer que a noção de self fica associada à construção discursiva de histórias pessoais, ou seja, o self depende das posições que são assumidas pelos interlocutores durante suas práticas discursivas. Ele é produto de trocas discursivas, nas quais as pessoas dão sentido ao mundo e às suas próprias ações. Uma vez que as trocas são situadas, o self é definido momento a momento nas interações, por meio dos modos como as pessoas posicionam a si mesmas e aos outros (Guanaes \& Japur, 2008).

$\mathrm{O}$ conceito de posicionamento refere-se, portanto, à dinâmica de como as pessoas são localizadas nas conversas, participantes em linhas de história construídas conjuntamente. Os posicionamentos são usados pelas pessoas enquanto navegam pelas múltiplas narrativas com as quais têm contato para lidar com as diversas situações em que se encontram. Quando falamos, nos posicionamos, somos posicionados e também posicionamos a pessoa de quem estamos falando (Souza, 2011). Por exemplo, se em uma conversa, uma pessoa for posicionada como dependente, seu choro pode ser entendido como um pedido de ajuda. Ao contrário, se a mesma pessoa for posicionada como dominadora, seu choro pode ser entendido como um protesto.

A Teoria do Posicionamento tem sua estrutura conceitual-metodológica baseada na tríade posição, força social da ação e linha de história (Guanaes, 2001; van Langenhoe \& Harré, 1999). Os três elementos desta tríade são responsáveis por sustentar o conceito de posicionamento, que tanto nos ajuda na compreensão da noção de self trazida pelos teóricos do posicionamento, quanto na compreensão do dinamismo dos processos conversacionais. A seguir procuramos dar visibilidade aos três conceitos. 
Posição, força social da ação e linha de história

Como já vimos anteriormente, ao assumir uma posição, o indivíduo traz para o momento interacional sua história repleta de particularidades. Ele interpreta o mundo e as situações através da posição assumida. Davies e Harré (1990) apontam que, ao falar a partir de uma posição, as pessoas trazem para o momento interacional a história de quem já ocupou diversas outras posições e se envolveu em inúmeras formas de discurso.

Uma posição reúne um repertório conceitual e localiza as pessoas dentro de um sistema de direitos e deveres, ou seja, para cada posição ocupada, existem normas, regras e expectativas individuais ou sociais (Guanaes \& Japur, 2008). Ao entrar nas conversações, cada pessoa tem múltiplas possibilidades de escolha de posição. Entretanto, as posições tendem a ser contextuais, ou seja, estão atreladas às situações e ao modo como são ativamente negociadas em cada interação.

Para Spink (2010), uma maneira possível de ilustrar as posições de pessoas é uma comparação com as múltiplas versões de curriculum vitae que encaminhamos para empregos. Se o destino do curriculum for uma empresa, por exemplo, certos elementos de nossa linha de história serão destacados. Se for para a universidade, outros pontos serão destacados.

Assim, quando nos engajamos em nossas conversações, dependendo do contexto, assunto e interlocutores, escolhemos elementos nossos que atendem ao momento interacional e abandonamos outros elementos, que podem ser requeridos em outras situações. Desse ponto de vista, podemos dizer que as diversas posições de self, por exemplo, vão se diferenciar de acordo com as normas sociais que regulam essas interações e com as situações específicas em que elas ocorrem (Guanaes \& Japur, 2003).

Todas as posições exercem uma força sobre o que as pessoas dizem ou fazem. A isto chamamos de força social da ação, que se refere ao “... poder presente nos enunciados na construção das práticas sociais e de realidades conversacionais" (van Langenhoe \& Harré, 1999). Em outras palavras, isso diz respeito às consequências práticas do ato de se posicionar e posicionar outros enquanto conversamos (Martins, 2017). O conceito se firma na ideia de linguagem em uso de Wittgeinstein (1975), na qual a linguagem é considerada uma prática social. Nessa lógica, quando as pessoas falam, elas realizam ações, nas quais posições são negociadas conforme propósitos sociais e que trazem implicações práticas para o momento interacional (Davies \& Harré, 1990)

Por fim, as linhas de história se desenvolvem a partir da conversa entre interlocutores durante um momento interativo específico e também a partir da sequência de coisas já ditas em outros relacionamentos e conversas anteriores. Numa conversa, quando posicionamos as pessoas ou somos posicionados, somos impelidos a usar uma linha de história equivalente à posição. Citando como exemplo, logo após um acidente, um indivíduo pode ser posicionado como o líder que coordenará a situação, e deste lugar, ser convidado a realizar atos heroicos correspondentes com a linha narrativa de um herói.

As linhas de história se referem a um grupo de significados que define os sentidos de uma posição num contexto específico. Os sentidos atribuídos à posição aparecem nas linhas de história trazidas pelas 
pessoas enquanto interagem e podem vir de experiências anteriores ou de discursos culturalmente disponíveis (van Langenove \& Harré, 1999). Isso quer dizer que, ao explorar a linha de história de uma pessoa, caminhamos para o entendimento de quais são os significados possíveis para ela, naquele momento, relativos a uma posição.

\section{TEORIA DO POSICIONAMENTO E TERAPIA FAMILIAR}

Com frequência, as pessoas procuram o espaço de terapia para aliviar suas angústias e sofrimentos com a noção de que o caminho para resolver suas questões está no trabalho com o indivíduo. No ambiente de terapia familiar, diversas são as vezes em que uma família traz como demanda a ajuda para solucionar dilemas relativos a um de seus membros, acreditando que a mudança do indivíduo problemático acarretará a solução do problema. De fato, o campo de terapia familiar recebeu contribuições de diversos âmbitos para fundamentar sua prática e, inicialmente, como tantos outros domínios, teve seus fundamentos influenciados pelos princípios tradicionais da ciência. Nesse sentido, o processo de terapia familiar era marcado por terapeutas interventivos, especialistas, neutros e com foco no indivíduo (Rapizo, 1996).

No final do século XIX e início do século $\mathrm{XX}$, a ciência que, antes, era orientada por um modelo que apontava para ideias como racionalidade, objetividade e neutralidade do conhecimento (Soar Filho, 1997), sofreu um giro paradigmático que deu espaço para uma ciência onde o homem não é apenas um mero observador capaz de descrever o mundo, mas coconstrutor de realidades, já que ao descre- ver e observar fenômenos, não pode desconsiderar seus próprios processos cognitivos (Rapizo, 1996).

Esse giro também atravessou o campo de terapia familiar e, na década de 1980, o domínio recebeu, dentre tantas influências, concepções que salientavam o papel da linguagem e dos processos de construção social da realidade. Isso possibilitou que propostas do movimento construcionista pudessem ser de grande serventia para a prática de terapia familiar. Rasera e Japur (2001) dizem que "A terapia marcada por uma influência construcionista tira o foco do interior da pessoa, suas cognições e constructos individuais, e enfatiza seu discurso em uma visão da linguagem como um processo social".

Em nossa compreensão, a utilidade da Teoria do Posicionamento para a prática clínica, especificamente aquela de orientação construcionista, está na relação entre a noção de self e o conceito de posição. A terapia familiar orientada por uma epistemologia construcionista social deixa de tratar problemas de maneira essencialista, na qual o foco é a mudança de aspectos internos, e passa a olhar para como as pessoas se constituem nas relações, através das posições que assumem e que outros atribuem a ela, aumentando o leque de descrições de si e suas possibilidades de ação no mundo.

Com base nessa compreensão, este artigo tem como objetivo dar visibilidade ao processo de construção de posições discursivas alternativas para a relação de uma mãe e um filho a partir do foco no processo de comunicação e do uso de uma metáfora em um contexto de terapia familiar. Especificamente, busca: (a) analisar a construção de diferentes posições discursivas para os membros da família em momentos específicos da sessão; (b) nomear os 
recursos discursivos utilizados pelas terapeutas no auxílio da construção dessas posições; e (c) analisar os efeitos dessas diferentes posições para o andamento da conversa terapêutica.

\section{METODOLOGIA}

\section{Delineamento Teórico-Metodológico}

O delineamento teórico deste artigo parte do Construcionismo Social, cujo foco é a produção de sentidos durante a conversação terapêutica em terapia familiar. Ao assumir uma postura construcionista social em pesquisa, partimos do pressuposto de que a realidade em que vivemos é criada nas relações, nas interações entre as pessoas e das pessoas com o mundo. A pesquisa sugere que não existe uma realidade universal, ao contrário, as versões de mundo que vivemos como realidade e a produção do conhecimento sobre elas é sustentada através de ações conjuntas, que se tornam parâmetros na produção de valores e expectativas e que assumem um caráter de realidade (McNamee, 2014).

O convite de McNamee (2014) é olhar para a pesquisa como um processo relacional que, ao invés de produzir verdades absolutas, produz novos sentidos sobre um determinado contexto. Em terapia familiar existem múltiplos discursos, atravessados por múltiplas verdades tantas quanto forem as vozes participantes, podendo inclusive concorrer entre si. Como terapeutas-pesquisadoras, pretendemos apresentar uma reflexão sobre as possibilidades de uso de conceitos teóricos propostos sobre posicionamento como sustentação da prática clínica. O artigo propõe, assim, coerente com o entendimento construcionista da teoria como prática (McNamee, 2014), envolver-se com a pergunta "de que maneiras essa inves- tigação é útil?". Estamos, aqui, compromissadas com essas premissas.

\section{Contexto do Atendimento}

Paola é uma mulher de 40 anos, solteira, vendedora em uma loja de joias. Ela é mãe de Fernando, 11 anos, estudante do $5^{\circ}$ ano. Ambos residem juntos em um condomínio situado numa cidade do interior de São Paulo e foram atendidos na clínica social de um instituto de formação de terapeutas familiares. O instituto oferece seus atendimentos trabalhando com duas terapeutas em campo e três terapeutas em equipe reflexiva (Andersen, 1996). O atendimento todo teve duração de sete sessões que foram gravadas e autorizadas mediante assinatura do TCLE (Termo de Consentimento Livre e Esclarecido). Os nomes dos participantes também foram alterados para que se mantenha o sigilo sobre suas identidades.

Paola chegou para nosso primeiro encontro descrevendo o quanto sua relação com o pai de Fernando foi sempre conturbada e cheia de brigas. Ela conta que não foi casada, mas que os conflitos já eram intensos desde a época da gravidez e se arrastaram ao longo de dez anos. Cansada das desavenças e preocupada com a saúde emocional do filho, procurou o sistema judiciário para resolver questões mais pontuais, como visitas, horários e pensão alimentícia. Paola ainda expõe que, no Fórum, foi orientada a participar de oficinas de pais e mediação de conflitos, porém relata que as medidas foram ineficazes para a questão da comunicação entre ela e o pai de Fernando. Por fim, concluiu por procurar um espaço de ajuda para o filho, entendendo seu sofrimento, já que era quieto e pouco se abria sobre os conflitos familiares. 
Fernando foi ao primeiro atendimento com a mãe e pareceu-nos bastante desconfortável. Quando convidados a sentarem-se, escolheu a mesma poltrona da mãe. Ficou atento à conversa, por vezes em silêncio e em outras contradizendo algumas falas da mãe. Quando o convidamos a falar, Fernando discordou sobre o mal que a desavença dos pais lhe fazia, ao contrário, pensava que tudo fosse normal, já que os conflitos eram anteriores ao seu nascimento. Disse também que costuma frequentar a casa do pai quinzenalmente, onde encontra as irmãs mais novas.

Continuamos na investigação de mais alguns detalhes do cotidiano de Fernando, tais como amigos, escola, brincadeiras preferidas e, por fim, perguntamos a ambos o que esperavam alcançar durante o processo de terapia. Inicialmente, Paola apontou que gostaria de cuidar do relacionamento entre ela, o pai e o filho. Entretanto, no transcorrer das sessões, Paola e Fernando puderam clarear e nomear pedidos para trabalhar nos encontros. Para Paola, o pedido era melhorar a comunicação com o filho. Para Fernando, o pedido era ser ouvido.

Escolhemos explorar alguns momentos do processo terapêutico de ambos, nos quais buscamos evidenciar a intervenção das terapeutas com foco no processo de comunicação, cujo resultado foi a mudança de posicionamentos mãe-filho, favorecendo que os pedidos iniciais fossem atendidos.

Usando a Teoria do Posicionamento como base para a análise, dividiremos nossa discussão em três momentos: (a) o problema, no qual apontaremos um estilo de comunicação truncada e não desejada pelos clientes; (b) a intervenção, na qual salientaremos como fomos construindo recursos que produziram a mudança no estilo de comunicação; e, por fim, (c) os efeitos, no qual apresentaremos recortes que possam evidenciar as repercussões da intervenção na comunicação dos clientes.

\section{O PROBLEMA}

Na primeira sessão, enquanto Paola e Fernando faziam o relato de suas histórias, por diversas vezes, suas falas se cruzavam na forma de embate. Se Paola contava algo que não agradava a Fernando, ele logo atravessava a conversa, contradizendo a mãe, e vice-versa. Paola frequentemente levava para a conversa o fato de ter vindo de uma cidade pequena no interior de outro estado, de costumes tradicionais. Dizia que seguia como mãe solo, sentindo-se unicamente responsável pelo sustento e educação do filho. Frisava também o quanto queria ver Fernando se transformar em uma pessoa de bem, comprometida e trabalhadora.

Acreditamos que estar só na educação do filho, as cobranças da cultura ocidental associadas ao papel de mãe e a história de relação com sua própria mãe contribuíram para que Paola assumisse algumas posições naquelas interações, tanto a posição socialmente reconhecida de ser mãe, quanto a variação dessa posição, que no caso de Paola durante as sessões era a de ser mãe metódica e exigente.

A partir dessas posições, Paola apresentava linhas de história conversacionais nas quais ela se posicionava como quem tinha o direito de ensinar, de quem sabia mais, ao passo que colocava Fernando na posição de filho, criança, irresponsável e sem comprometimento, e posicionava-o como quem tinha o dever de ouvir mais e aprender com ela. 
Fernando, por sua vez, ao rejeitar da mãe algumas posições como a de irresponsável e sem comprometimento, se esforçava por assumir, na conversa, a posição de pessoa autônoma e madura, trazendo consigo uma linha de história que o posicionava como um menino que sabe se cuidar e que queria o direito de se expressar e ter seu ponto de vista considerado.

A despeito das intenções positivas dos interlocutores, esse jogo de posicionamentos, durante boa parte das sessões, trazia consequências para a forma como a conversa se desenvolvia, ou seja, uma força social de ação que resultava em uma comunicação truncada, de conversas cruzadas, nas quais Paola falava muito, apontava erros e acusava, enquanto Fernando interrompia, se defendendo.

$\mathrm{O}$ recorte abaixo ilustra o estilo conversacional em um determinado momento da quarta sessão, quando fizemos a tentativa de organizar, com ambos, a rotina de Fernando em casa através de combinados. Isso aconteceu da seguinte forma:

Letícia (terapeuta): Para essa questão dos combinados, a gente pode ouvir o Fernando junto com você?

Paola: Pode, porque ele tem uns cinco dias que não quer atender (o telefone), sabe?

Fernando (interrompendo): Não! Por causa que eu estou brincando!

Eneida (terapeuta): Não. Não por esse caminho. Vamos ouvir de um outro jeito. Você... a gente tá falando de algumas sugestões que você (apontando para Paola) pode dar e ele também.

Letícia (terapeuta): Que podem ajudar você a ficar mais segura com essa parte...
Paola (fala por cima): É tipo assim: mamãe, tô aqui brincando na quadra ... todo mundo olha (o Fernando) pra mim. Inclusive o segurança, porteiro.

Eneida (rindo): Você tem uma equipe...

Paola (em tom de ameaça, olhando para o filho): Agora vou pôr câmeras lá em casa, então vai ficar perfeito (...) já tem lá no meu condomínio, eles veem tudo o que ele faz.

Fernando (interrompe se defendendo): Nada a ver mãe! Eu e meus amigos ... a gente sabe onde que vê as câmeras e não tem ninguém olhando!

Paola: Não! Mas se eu pedir para monitorar igual...

Fernando (interrompe, irritado): Eles não vão ficar me monitorando...

Com posições como as descritas acima resultou difícil promover um diálogo que envolvesse escuta mútua, de modo que todo sistema terapêutico se afastava do seu pedido/objetivo inicial: o de que cada um pudesse falar e ser ouvido.

\section{OS RECURSOS}

Este tópico refere-se aos recursos que utilizamos ao longo do atendimento e que foram úteis para a construção de novas posições para Paola e Fernando. Distinguimos esses recursos em três movimentos que, em nosso entendimento, geraram o efeito desejado por mãe e filho desde o início, ou seja, uma mudança na qualidade de sua interação: (a) atender ao pedido de Fernando de ser ouvido;

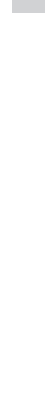


(b) deslocar a comunicação do conteúdo para o processo; (c) uso de metáfora para construir novas posições para mãe e filho.

\section{Primeiro Movimento: Atendera o pedido de Fernando de ser ouvido}

Durante o quarto encontro, Fernando contou um pouco sobre sua semana. Dentre as narrativas, decidimos explorar elementos de sua rotina, como horário de escola, atividades em tempo livre, amigos etc. Em determinado momento da conversa, Fernando falou sobre uma série de TV de que gostava muito, Teen Wolf, cuja história gira em torno de um personagem principal, adolescente, que foi mordido por um lobisomem, tornando-se um também. Depois disso, o personagem precisa lidar com todos os desafios da nova identidade, além de lidar com a adolescência. Fernando, sentindo-se empolgado, começa a narrar a história da série explicando-nos como funciona o sistema dos lobos. Segundo ele, existe o lobo Alpha, que é o líder, aquele que ensina e comanda a alcateia, e os Betas, que são seus seguidores, aprendizes. Fernando explica que todos fazem parte de uma alcateia que, segundo ele, "é como se fosse a família deles".

Ao entrar na história dos lobos genuinamente curiosas, através de perguntas e demonstrando interesse, estávamos atendendo, na sessão, ao pedido de Fernando para ser ouvido. Em nossa percepção, este era um jeito de valorizar sua fala, entender a importância daquela história para ele, e inclusive de ocuparmos a posição de "Beta". Dito de outro modo, naquele momento, fizemos como o lobo que aprende, que segue junto, enquanto ele, alpha, liderava a conversa, ao nos ensinar sobre a série de TV.
Compreendemos que acompanhar Fernando assumindo a posição de quem estava aprendendo nos distanciou da posição de especialistas que, em muitos casos, pode trazer uma linha de história conversacional próxima da ciência tradicional, de um saber especial, técnico e privilegiado sobre o cliente. Ao mesmo tempo, isso nos aproximou de um estilo de conversa onde o cliente é posicionado como o especialista (Anderson \& Goolishian, 1993; Doricci, Crovador, \& Martins, 2017), no qual todos aprendem com todos. $\mathrm{Na}$ posição de terapeutas "betas", permitimos que Fernando assumisse uma posição mais distante daquela em que filho só aprende. Ele experienciava a possibilidade de ser um "filho-alpha". Ali, ele nos ensinou sobre uma série de TV que, para ele, é importante e, ao mesmo tempo, contava sobre si mesmo, tomando uma posição de quem tem conhecimentos a contribuir na conversa.

Eneida: Qual que é? Não conheço.

Fernando (fala, empolgado): $E$ a melhor série!

Letícia: A melhor série?

Fernando: É!

Eneida: Por quê?

Fernando: Porque é muito legal. Tava até mostrando pra minha mãe que tem uma pulseira ... e tem uma alcateia que é o grupinho deles...

Eneida: $O$ que é uma alcateia, Fernando?

Fernando: É tipo, tem o lobo Alpha que é o líder e tem os betas.

Eneida: Lobo líder, você falou? 
Fernando: É, aí quando o lobo Alpha morde o beta, ele vira da alcateia dele. Alcateia é como se fosse a família deles.

O trecho mostra um processo discursivo de posicionamento de Fernando como alguém que tem algo a contribuir para aquela conversa. Note como essa posição não é nomeada ali, mas ela é construída enquanto os interlocutores falam sobre a temática proposta pelo garoto de uma determinada forma, engajada e interessada. Posicionar-se é sempre um processo recursivo. Quando nós, terapeutas, posicionamos Fernando assim, construímos para nós, ao mesmo tempo, posições de pessoas que podem com ele aprender. Isso tem implicações, ou seja, o processo de posicionar tem força social que, neste caso, afetou o estilo de comunicação na sessão, no qual foi possível conversar com Fernando sobre seus interesses, sentimentos, necessidades. Ainda, a história dos lobos trazida por ele foi usada como metáfora em outro momento na sessão, extremamente útil para que mãe e filho pudessem visualizar posições que privilegiam um estilo de comunicação desejável para ambos. Esse momento está mais bem descrito adiante, no tópico “Terceiro Movimento: Uso da Metáfora Para Construir Novas Posições Para Mãe e Filho".

\section{Segundo Movimento: Deslocar a Comunicação do Conteúdo para o Processo}

Depois de escutar toda a história sobre lobos e alcateias, passamos a fala para Paola, que escolheu aproveitar seu momento relatando o quanto estava insatisfeita com a rotina do filho. Paola mencionou que, no ano anterior, a rotina era perfeita, com horários bem organizados, atividades extracurriculares pagas pelo pai de Fernando e que sua única preocupação era deixar Fernando nas atividades pela manhã. Depois, o pai o deixava na escola e ela só ia buscá-lo no final da tarde. Entretanto, a nova rotina incluía Fernando ir à escola pela manhã e ficar sozinho em casa no período da tarde, já que seu pai não podia mais pagar as atividades.

Ao descrever as tardes de Fernando, Paola ocupou a posição de mãe metódi$c a$, que exige obediência e prestação de contas do filho. Dessa posição, ela alternava entre falar o quanto estava preocupada de estar no trabalho pensando no filho sozinho em casa e falar que não estava conseguindo lidar com a liberdade dele: "assim, ele tá achando que já tem 18 anos!". Ela começou uma conversa sobre Fernando sair de casa sozinho e sem autorização, de tarefas não cumpridas e irresponsabilidades, "ele não cumpre nem a obrigação que é estudar".

$\mathrm{Na}$ posição de terapeutas que acreditam que as pessoas, em suas práticas discursivas, produzem realidades sociais e psicológicas (Davies \& Harré, 1990), entendemos que as falas de desqualificação não ajudariam a produzir a realidade desejada por mãe e filho, isto é, melhorar a comunicação entre ambos. Foi assim que optamos por interromper Paola e tentar deslocar o assunto do conteúdo, ou seja, insatisfação com filho e sua rotina, para o processo, ou seja, se as coisas não estão boas do jeito que estão, como conversar para combinar um novo jeito de seguirem juntos.

Nessa primeira tentativa de conversar sobre o "como", Paola e Fernando se engajaram no assunto de como avisar um ao outro sobre o que estavam fazendo no dia a dia. Novamente, Paola tentou trazer um conteúdo de desqualificação, dizendo que Fernando não estava cumprindo a parte dele 
de relatar sua rotina através das mensagens. Dizia que ele estava passando dos limites e, como consequência dessa conversa, Fernando começou a atravessar as falas da mãe defensivamente, o que tornou a comunicação truncada e cheia de acusações. Estavam, ali, ocupando suas posições discursivas mais tradicionais. Novamente, insistimos na ação de deslocar do conteúdo ofensivo e ir em direção ao processo de como ambos estavam se comunicando:

Letícia: ... a gente tem alguns encontros para ajudá-los a melhorar com aqueles pedidos.

Paola (falando junto): $E$, pra melhorar com aqueles mesmos motivos.

Letícia: Isso, como é você ouvir? Como a gente conversa melhor? Aí eu fico imaginando, vocês estão vendo? Conseguem se perceber nesse processo? Um conversa e depois o outro conversa e entra na conversa do outro (...) como esse processo ajuda no pedido de vocês?

Fernando: Porque a gente tá conversando e falando as coisas que a gente discorda

Paola: Mas tem que escutar ...

Letícia: Isso, mas vocês viram como um cruza a conversa do outro?

Paola: Assim, não dá ...

Letícia: A sua mãe fala, fala, fala e você entra no meio ...

Paola: E não tá certo ... eu entro no meio.

Letícia: E como isso ajuda no pedido de vocês? 'Eu quero ser ouvido e aprender a conversar'. Ajuda?

Fernando: Não.
Nesse momento ambos aceitaram o convite para a posição de mãe e filho atentos ao modo de se comunicar. É possível notar na fala de Paola "Mas tem que escutar" esse deslocamento de posição, que vai de uma mãe metódica que tem o direito de falar e quer contar histórias sobre o filho e vai para uma mãe que entende a importância do como conversar e que, para a conversa fluir, não basta apenas assumir a posição de mãe que fala, mas também a de mãe que escuta. Fernando, que antes, na posição de filho irresponsável, para se defender, atravessava as falas da mãe, depois do convite para olhar o processo, também compreendeu que se a família quisesse ter o pedido de melhorar a comunicação atendido, sua posição também teria que mudar, ou seja, ora assumir a posição de quem vai falar e ora de quem vai escutar.

Insistir para que os clientes se deslocassem do foco no conteúdo e se percebessem no processo de comunicação (cruzado, truncado, onde um não escuta o outro) trouxe uma força de ação que resultou em uma conversa mais fluida, tranquila, com pausas maiores e com mais espaço para explorar sentidos. A seguir, relatamos como o último movimento terapêutico, o uso de metáfora, deu continuidade para o movimento de focar no processo e foi essencial para a construção de posições que ajudaram mãe e filho nos pedidos de melhorar a comunicação e ser ouvido.

Terceiro Movimento: Uso da Metáfora na construção de Novas Posições para Mãe e Filho

A metáfora é uma ferramenta linguística que pode ser usada para abordar situações difíceis ou muito 
abstratas; uma linguagem mais acessível para os clientes. Para as autoras Paschoal e Grandesso (2014), a metáfora é como uma figura de linguagem onde uma palavra ou expressão é emprestada de um contexto para dar sentido a outro, abrindo espaço para a negociação e a criação de novos sentidos. Fernando, no início da sessão, contou sobre uma série de TV da qual gostava muito e enquanto relatava detalhes da série, foi nos explicando e ensinando sobre uma infinidade de elementos que posteriormente foram muito úteis no processo de negociar posições entre mãe e filho que os ajudariam a evoluir no estilo de comunicação desejado. Por exemplo, Fernando nos ensinou que alcateia é como se fosse uma família; que lobo alpha é quem lidera, quem ensina; lobos betas são como discípulos, seguidores, e podem se tornar alphas um dia; que lobos ômegas são sozinhos e não têm família, entre outras coisas.

Depois da intervenção que fez com que ambos se percebessem no processo de comunicação conflituosa, aproveitamos alguns elementos da história dos lobos trazida por Fernando como metáfora para que mãe e filho pudessem visualizar como ficariam suas posições na comunicação desejada:

Paola: Eu sou muito impulsiva, ele também. Todo mundo querendo liderar.

Eneida: É tudo alpha, né?

Paola: Aí fica difícil.

Eneida: E como é alternar? Uma hora eu sou alpha, e eu tô falando, e outro é beta e está ouvindo, e depois a gente troca? Porque se não ninguém ouve, né?

Fernando: O beta tem que ouvir.
Eneida: Então... tem que trocar as posições.

Em nossa compreensão, mergulhar na história dos lobos foi importante para coordenar quatro posições para mãe e filho: de ouvir e de falar, e de aprender e ensinar. No primeiro momento, as posições de alpha e beta foram usadas como metáfora para exemplificar que, em uma conversa, tem hora de ouvir e tem hora de falar, como destacado no trecho acima. Em um segundo momento, as posições alpha e beta serviram como metáfora para ilustrar que todos, independente das posições sociais mais tradicionais e rígidas que ocupam (mãe e filho, por exemplo), têm coisas para ensinar e coisas para aprender:

Letícia: Você trouxe a questão do alpha. O que faz o alpha?

Fernando: Ele lidera.

Letícia: O que faz o beta?

Fernando: Aprende.

Letícia: Você não acha que todo mundo tem coisas pra ensinar? E que vocês podem negociar essas posições enquanto conversam? Eu tenho certeza de que sua mãe aprende um monte de coisas com você.

Como já dissemos anteriormente, ao assumir uma posição, as pessoas veem e agem no mundo a partir da posição assumida. Ao oferecer novas posições, nesse caso, alpha e beta, mãe e filho puderam visualizar um novo modelo de conversa que seria útil nas negociações dos mais diversos assuntos, favorecendo uma relação preferida entre ambos. Os efeitos dos movimentos terapêuticos serão descritos no tópico a seguir. 


\section{OS EFEITOS}

Embora o conteúdo trazido pelos clientes nas sessões de terapia seja importante, entendemos que, neste atendimento, ele se tornou secundário. A grande virada se deu quando mãe e filho se perceberam no processo de comunicação, a partir dos recursos utilizados por nós como terapeutas. Consideramos que, na posição de terapeutas amparadas pelo discurso construcionista social, insistimos no lugar de acompanhantes legítimas de nossos clientes em suas histórias. Com o foco no processo e fazendo uso da metáfora, alcançamos como efeito que os clientes se reconhecessem em novas posições discursivas naquela interação, e que possibilitaram outras formas de ação na relação mãe e filho:

Letícia: E Paola? O que você acha disso? Dá pra negociar? (posições alpha e beta)

Paola: Nossa! Eu achei maravilhoso isso que vocês estão fazendo. A gente não tinha pensado nisso, né filho?

Fernando: Aham, lá em casa a gente não estava se olhando.

A partir dessas novas posições, alpha e beta, de quem pode ouvir e falar, ensinar e aprender, os dois usaram o espaço da terapia para combinar assuntos da rotina da família de forma tranquila e fluida, que pudesse favorecer a autonomia de Fernando dentro dos limites de sua idade e fazer com que Paola se sentisse mais tranquila e segura, mesmo que Fernando ficasse sozinho em casa. Eles também assimilaram, a partir das novas posições discursivas, que cada um tem um jeito e que é possível negociar, na relação, a coexistência dessas diferenças. Paola deixou isso claro quando comentou: "Nossas discussões são falta de conversar e combinar. Porque eu sou mãe e quero ver ele assim ... do meu jeito. E não é assim".

Fernando também reconheceu a importância das posições alpha e beta na relação como fundamentais para a sobrevivência da alcateia/família. Diz sobre isso da seguinte forma:

"Tia, enquanto a gente tava falando de alpha e beta, eu tava pensando assim, óh, que eu e minha mãe, a gente estava sendo ômegas. E os ômegas são aqueles que não têm o alpha. Ficam sozinhos e são sempre os que morrem. Porque eles não têm ninguém pra ensinar e proteger eles".

A força social da ação decorrente de ambos se reconhecerem nessas posições apareceu no estilo de comunicação que se seguiu no restante da sessão. Paola, antes, costumava dominar as falas na sessão amparada em sua posição tradicional de mãe, metódica, impedindo o fluxo de conversa. Agora, como lobo beta, passou a escutar, sem interromper, sobre as necessidades do filho e a aprender com ele o que era importante para sua rotina seguir de um jeito que fosse satisfatório para os dois. Isso propiciou a Fernando não mais adotar uma postura defensiva nas conversas. Em razão disso, conseguiu ocupar calmamente a posição de lobo beta que, ao invés de cruzar as falas da mãe, passou a escutar suas sugestões. Ao mesmo tempo, construímos juntos também a possibilidade de o garoto ocupar a posição de lobo alpha em alguns momentos, alguém que pode ensinar e contribuir na conversa, seguro de que suas falas serão ouvidas e valorizadas. 


\section{CONSIDERACÕES FINAIS}

Gostaríamos de finalizar este artigo a partir da reflexão construcionista social que trouxemos anteriormente sobre a importância da construção do conhecimento em terapia familiar: "de que maneiras essa investigação é útil?". Em nosso entendimento, a discussão trazida aqui nos ajuda a esclarecer como conceitos teóricos complexos - no caso, advindos da Teoria do Posicionamento (van Langenhove \& Harré, 1999) - podem servir como sensibilidades, inspirações e sustentação para a atuação na prática clínica. Nossa análise permite dar visibilidade prática ao entendimento do self como associado à construção discursiva de histórias pessoais, dependente das posições assumidas pelos interlocutores durante suas práticas discursivas e definido momento a momento nas interações. Portanto, nosso convite como terapeutas orientadas por essa teoria é para a reflexão sobre quais realidades conversacionais criamos ao interagirmos com nossos clientes não como unidades fixas e estáticas, mas como tendo identidades que se constituem nas relações, em processos de posicionamento social. Em nossa experiência acompanhando a família, essa sensibilidade teórica foi uma forma de criar oportunidades, por meio da construção de novas posições, para que mãe e filho encontrassem diferentes descrições de si, nas quais puderam se conhecer de maneiras diferentes daquelas que produziam o conflito e, assim, aumentar suas possibilidades de estar em relação.

Além disso, a Teoria do Posicionamento também nos foi útil como instrumento teórico-metodológico durante a análise do material coletado no atendimento para avançarmos na compreensão de como ocorreu o pro- cesso de construção das posições discursivas que produziram a mudança na relação mãe/filho. Com esse enquadre, pudemos tornar visíveis tanto as posições iniciais dos clientes, cujas necessidades de falar e ser ouvido eram mutuamente desrespeitadas, quanto as posições das terapeutas na busca de recursos discursivos que fizessem emergir as novas posições e descrições de si mesmos.

Considerando o fato de que os jogos de posicionamento são sempre recursivos, este artigo, ademais, abre reflexões a respeito dos efeitos do posicionamento do terapeuta ante o cliente. Com isto, queremos dizer que, ao construir posições para os clientes, nós, terapeutas, também estamos nos posicionando e construindo nossas próprias posições. Em nosso atendimento, por exemplo, enquanto ocupávamos a posição de terapeutas "betas", aprendendo e seguindo junto com Fernando, abríamos espaço para que ele assumisse a posição "alpha", na liderança da conversa. Nessa situação, atribuímos a Fernando o título de especialista de sua própria história (Anderson \& Goolishian, 1993; Doricci, Crovador,\& Martins, 2017). Embora o artigo tenha pincelado alguns dos efeitos dos posicionamentos das terapeutas, o foco da análise deste trabalho é voltado para a família. Fica em aberto, como um caminho possível para pesquisadores interessados no posicionamento, a análise de como os terapeutas são uma parte ativa na construção do processo de posicionamento.

No trânsito entre a pesquisa e a prática, entendemos que o artigo é uma possibilidade de exercitarmos o que Rasera e Guanaes (2006) chamaram de "o terapeuta como produtor de conhecimentos", compreendendo que articular experiências clínicas vividas de maneira intensa em outros meios 
de comunicação pode contribuir para o campo de terapia familiar e para a experiência de outros terapeutas. Desejamos, assim, que este artigo seja também um convite para a continuidade de diálogos como este, para que mais profissionais compartilhem suas experiências práticas de modo refletido e criativo.

\section{REFERÊNCIAS}

Andersen, T: (1996). Processos Reflexivos. Rio de Janeiro: Instituto NOOS/ ITF.

Anderson,H. \& Goolishian,H. (1993).O cliente é o especialista: uma abordagem para a terapia a partir de uma posição de não saber. Nova Perspectiva Sistêmica, 2(3), 08-21.

Davies, B. \&Harré, R. (1990). The discursive production of selves. Journal for the Theory of Social Behaviour, 20(1), 43-63.

Doricci, G. C., Crovador, L. F., \& Martins, P. P. S. (2017). O Especialista relacional na terapia familiar de fundamentação epistemológica construcionista social. Nova Perspectiva Sistêmica, 59, 37-51.

Guanaes, C. (2001). O processo de produção de sentidos no contexto terapêutico de um grupo ambulatorial de curta duração com pacientes psiquiátricos. São Paulo: FAPESP.

Guanaes, C. \& Japur, M. (2003). Construcionismo Social e Metapsicologia: um diálogo sobre o conceito de Self. Psicologia: Teoria e Pesquisa, 19(2), 135-143.

Guanaes, C. \& Japur, M. (2008). Positioning theory: moral contexts of intentional action (resenha). Nova Perspectiva Sistêmica, 31, 109-112.

Hollway, W. (1984). Gender difference and the production of subjectivity. In J. Henriques, W. Hollway, C.
Urwin, C. Wenn, \& V. Walkerdine (Eds.), Changing the subject: Psychology, social regulation and subjectivity (pp. 227-263). London: Methuen. McNamee, S. \& Gergen, K. (1999). Relational responsibility: resources for sustainable dialogue.Thousand Oaks: Sage Publications.

McNamee, S. (2014). Construindo conhecimento / construindo investigação: coordenando mundos de pesquisa. In C. Guanaes-Lorenzi, M. S. Moscheta, C. M. Corradi-Webster, \& L. V. Souza (Orgs.), Construcionismo social: discurso, prática e produção de conhecimento (pp. 105- 131). Rio de Janeiro: Editora Noos.

Oliveira, Z. M. R., Guanaes, C., \& Costa, N.R.A. (2003). Discutindo o conceito de jogos de papel: uma interface com a teoria do posicionamento. In M. C. Rossetti-Ferreira, K. S. Amorin, A. P. S. Silva, \& A.M. A. Carvalho (Org.), Rede de significações: uma nova perspectiva teórico-metodológica (pp. 69-80). Porto Alegre: Artes Médicas.

Paschoal, V. \& Grandesso, M. (2014). O uso de metáforas em terapia narrativa: facilitando a construção de novos significados. Nova Perspectiva Sistêmica, 48,24-43.

Rasera, E. \& Guanaes, C. (2006). O terapeuta como produtor de conhecimentos: contribuições da perspectiva construcionista social. Nova Perspectiva Sistêmica, 26,76-85.

Rasera, E. F \& Japur, M. (2007).Grupo como construção social: aproximações entre construcionismo social e terapia de grupo. São Paulo: Vetor.

Rasera, E. \& Japur, M. (2001). Contribuições do pensamento construcionista para o estudo da prática grupal. Psicol. Reflex. Crit. [online], 14(1), 201-209. 
Rapizo, R. (1996). Terapia Sistêmica de Família. Rio de Janeiro: Instituto NOOS.

Soar, E.J. (1997). Varius multiplex multiformis: espistemologia do self no pós-modernismo. Dissertação de Mestrado, Programa de Pós-graduação em Psicologia, Universidade Federal de Santa Catarina, Florianópolis, SC.

Souza, L. V. (2011). Construindo cuidado: a relação com os profissionais da saúde nas práticas discursivas de pessoas diagnosticadas com transtornos alimentares. Tese de Doutorado, Faculdade de Filosofia, Ciências e Letras de Ribeirão Preto, Universidade de São Paulo, Ribeirão Preto.

Spink, M. J. (2010). Linguagem e produção de sentidos no cotidiano [online]. Rio de Janeiro: Centro Edelstein de Pesquisas Sociais,72 p. ISBN: 978-85-7982-046-5. Available from SciELO Books <http:// books.scielo.org>.

Van Langenhove, L: \& Harré, R. (1999). Introducing positioning theory: the dinamic of social episodes. In $\mathrm{R}$. Harré\& L. van Langenhove (Eds.), Positioning theory: moral contexts of intentional actions (pp. 14-31). Oxford: Blackwell Publishers.

Wittgenstein, L. (1975). Investigações Filosóficas. São Paulo: Abril Cultural. (Coleção "Os Pensadores")

\section{LETíCIA DE AZEVEDO POZZER}

(https://orcid.org/0000-0003-39127714)

É formada em Comunicação Social, Terapeuta Familiar e de Casal e Mediadora de Conflitos pelo Instituto Conversações/ Ribeirão Preto/SP.

E-mail: leticiazpz@gmail.com

\section{ENEIDA DE DUARTINA FERNANDES NOVAES}

(https://orcid.org/0000-0003-17111711)

É psicóloga clínica e organizacional, CTB (Certified Bioenergetic Therapist), Instituto Lumen, Ribeirão Preto, filiado ao IIBA (Internacional Institute of Bioenergetic Analylis). Supervisora em Análise Bioenergética pelo IABSP, coordenadora de Grupos de Movimento. Certificação Internacional em Práticas Colaborativas e Dialógicas (Interfaci/Houston Galveston Institute/ Taos Institute. Docente do Instituto Távola de Psicanálise/ Ribeirão Preto. Terapeuta Familiar e de Casal pelo Instituto Conversações/ Ribeirão Preto/SP.

E-mail: eneidafernandes.psico@gmail. com 